\title{
Resting heart rate at hospital admission and its relation to hospital outcome in patients with heart failure
}

\author{
Agnieszka Kapłon-Cieślicka ${ }^{1}$, Paweł Balsam ${ }^{1}$, Krzysztof Ozierański ${ }^{1}$, \\ Agata Tymińska ${ }^{1}$, Michał Peller ${ }^{1}$, Michalina Galas ${ }^{1}$, Marcin Wyzgał ${ }^{1}$, \\ Michał Marchel ${ }^{1}$, Jarosław Droż $\dot{z}^{2}$, Grzegorz Opolski ${ }^{1}$ \\ ${ }^{1} 1^{\text {st }}$ Chair and Department of Cardiology, Medical University of Warsaw, Warsaw, Poland \\ ${ }^{2}$ Department of Cardiology, $1^{\text {st }}$ Chair of Cardiology and Cardiac Surgery, \\ Medical University of Lodz, Lodz, Poland
}

\begin{abstract}
Background: Resting heart rate (HR) has been proven to influence long-term prognosis in patients with chronic heart failure (HF). The aim of this study was to assess the relationship between resting HR at hospital admission and hospital outcome in patients with HF.

Methods: The study included Polish patients admitted to hospital due to HF who agreed to participate in Heart Failure Pilot Survey of the European Society of Cardiology.

Results: The final analysis included 598 patients. Median HR at hospital admission was $80 \mathrm{bpm}$. In univariate analyses, higher HR at admission was associated with more frequent use of inotropic support $(p=0.0462)$ and diuretics $(p=0.0426)$, worse clinical (New York Heart Association - NYHA) status at discharge $(p=0.0483)$, longer hospital stay $(p=0.0303)$ and higher in-hospital mortality $(p=0.003)$. Compared to patients who survived, patients who died during hospitalization ( $n=21 ; 3.5 \%$ ) were older, more often had a history of stroke or transient ischemic attack and were characterized by higher NYHA class, higher HR at admission, lower systolic and diastolic blood pressure at admission, lower ejection fraction, lower glomerular filtration rate, and lower natrium and hemoglobin concentrations at hospital admission. In multivariate analysis, higher HR at admission (OR 1.594 [per 10 bpm]; 95\% CI 1.061-2.395; $p=0.0248)$ and lower natrium concentration at admission (OR 0.767 [per $1 \mathrm{mmol} / \mathrm{L}]$; 95\% CI 0.618-0.952; $p=0.0162$ ) were the only independent predictors of in-hospital mortality. Conclusions: In patients with HF, higher resting HR at hospital admission is associated with increased in-hospital mortality. (Cardiol J 2014; 21, 4: 425-433)
\end{abstract}

Key words: heart rate, heart failure, prognosis, in-hospital mortality, hyponatremia

\section{Introduction}

Over the last few decades, the incidence and prevalence of chronic heart failure (HF) have been constantly increasing. This is a result of growing life expectancy and aging of modern societies, as well as advances in the treatment of acute coronary syndromes which lead to an increased number of survivors with left ventricular dysfunction [1].

Randomized clinical trials and large-scale registries are both helpful research tools. However, contrary to clinical trials, the advantage

Address for correspondence: Paweł Balsam, MD, $\mathrm{PhD}, 1^{\text {st }}$ Chair and Department of Cardiology, Medical University of Warsaw, Public Central Teaching Hospital in Warsaw, ul. Banacha 1a, 02-097 Warszawa, Poland, tel: +48 225992958 , fax: +48 2259919 57, e-mail: pawel.balsam@me.com

Received: 02.07.2013 Accepted: 14.09.2013 
of registries is that they reflect real-life patient populations. The aim of the Heart Failure Pilot Survey of the European Society of Cardiology was to assess clinical profile, pharmacotherapy and clinical course in HF patients across Europe [2].

Despite recent progress in pharmaco- and electrotherapy, prognosis in HF remains poor. The Systolic Heart Failure Treatment with the If Inhibitor Ivabradine Trial (SHIFT) demonstrated that in patients with chronic systolic HF higher resting heart rate (RHR) was associated with worse long-term prognosis [3]. The aim of this study was to assess the impact of RHR at hospital admission on short-term outcome in a Polish population of patients hospitalized for HF, based on data from the Heart Failure Pilot Survey.

\section{Methods}

\section{Study population}

The Heart Failure Pilot Survey was conducted by the European Society of Cardiology within the scope of the EURObservational Research Programme. It was a prospective, multicenter, observational survey of HF patients in 12 European countries. The survey included adult (i.e. over 18 years old) patients with $\mathrm{HF}$ - both, outpatients with $\mathrm{HF}$ seen in ambulatory care, as well as patients admitted to hospital for acute or chronic HF. There were no specific exclusion criteria. Patients were enrolled in the study if they presented to hospital or outpatient clinic on one particular day of the week (chosen by the participating center) from October 2009 to May 2010.

Data regarding demographics, HF etiology and severity, clinical presentation, concomitant diseases, diagnostic tests' results, previous and current treatment and - in case of inpatients - clinical course of index hospitalization were collected in 136 European cardiology centers, including 29 centers from Poland, and entered anonymously to on-line electronic Case Report Forms.

The survey was approved by the local Ethical Review Board. All the patients included into the survey were provided with detailed information on the aim, scope and methodology of the study. Signed informed consent was obtained from each of them.

The current analysis included Polish population of Heart Failure Pilot Survey and only inpatients (i.e. patients who were admitted to hospital). In order to assess the prognostic significance of baseline RHR, patients presenting with bradyarrhythmia or ventricular tachyarrhythmia as a rea- son for HF decompensation and index hospitalization, were excluded from the analysis.

\section{Study endpoints}

The primary endpoint was death during index hospitalization. Secondary endpoints included duration of hospital stay, time in Intensive Cardiac-Care Unit (ICCU), need for inotropic support and diuretic treatment, and clinical status expressed as New York Heart Association (NYHA) class at hospital discharge.

\section{Statistical analysis}

Categorical data were presented as number of patients and percentages. For ordinal variables and non-normally distributed continuous variables, median value and interquartile range (IQR) were used. Type of distribution was calculated by Shapiro-Wilk test with an alpha level set at 0.05 . Significance of differences between groups was determined by Fisher's exact test for categorical variables and Mann-Whitney U test for ordinal or non-normally distributed continuous variables. To determine the risk factors of in-hospital mortality, univariate and multivariate logistic regressions were performed. In multivariate logistic regression model all factors with $\mathrm{p}$ values lower than 0.1 in univariate analyses were used. Statistical significance was considered for $\mathrm{p}$ values lower than 0.05. Statistical analyses were performed using SAS software, version 9.2.

\section{Results}

\section{Study group selection}

Out of 5,118 patients included in the Heart Failure Pilot Survey across Europe, 893 patients were enrolled in Polish centers. In the Polish population of the registry, there were 650 inpatients. Thirty patients were admitted to hospital due to ventricular tachyarrhythmia and 21 patients due to bradyarrhythmia - those patients were excluded from the analysis. Data regarding RHR at hospital admission were missing for one of the remaining patients. Therefore, the final analysis included 598 patients hospitalized due to HF.

The flow chart of patient enrollment in the study is shown in Figure 1.

\section{Study group characteristics}

Baseline characteristics of the study group are presented in Table 1. Median age in the analyzed group was 69 (IQR: 58-78) years, $386(64.6 \%)$ patients were male. In 358 (59.9\%) patients HF was assumed to have ischemic etiology and in 


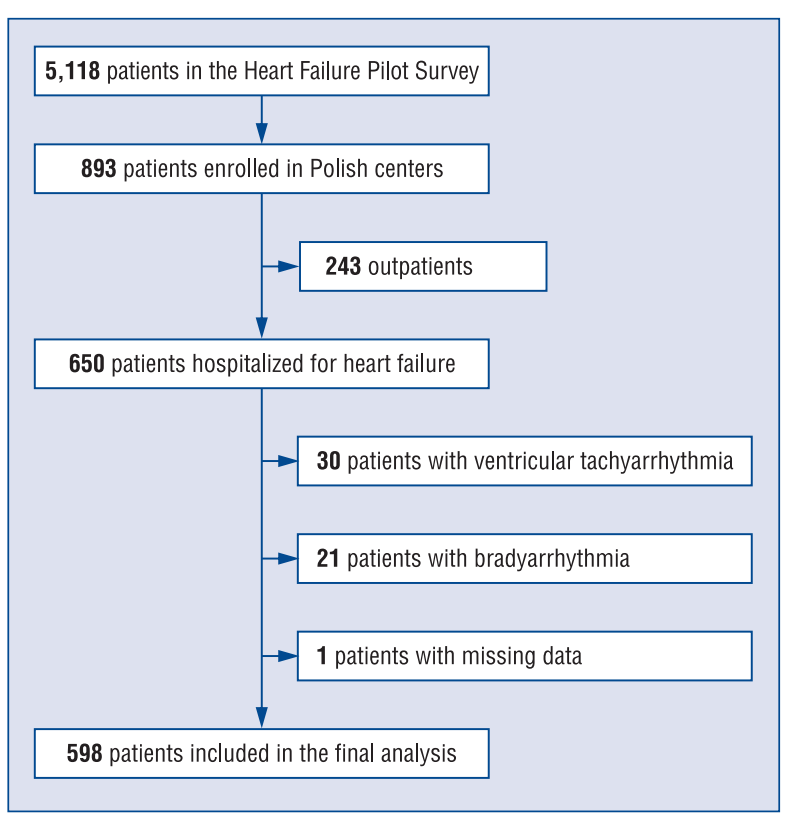

Figure 1. Flow chart of patient enrollment in the current analysis.

$242(40.5 \%)$ patients this had been previously confirmed by coronary angiography. Other causes of $\mathrm{HF}$ in the study group were: valvular heart disease (72 [12.0\%] patients), hypertension (66 [11.0\%]), dilated cardiomyopathy (59 [9.9\%]) and tachycardia-induced cardiomyopathy (9 [1.5\%]). In $34(5.7 \%)$ patients the etiology of HF was not defined by investigators.

The most common reason for HF decompensation leading to index hospitalization was acute coronary syndrome (in 179 [30.0\%] patients). Other triggering factors of $\mathrm{HF}$ decompensation leading to index hospitalization were: atrial fibrillation (AF) (103 [17.3\%] patients), uncontrolled hypertension (91 [15.2\%]), HF treatment non-compliance (89 [14.9\%]), infection (51 [8.5\%]), renal dysfunction (43 [7.2\%]), anemia (29 [4.9\%]), iatrogenic effect (7 [1.2\%]) and "other" causes (240 [40.2\%]) — with a possibility to name more than one reason of $\mathrm{HF}$ decompensation for each patient.

Median RHR at hospital admission was 80 (IQR: 70-100) bpm. Electrocardiogram at hospital admission was available for 576 patients, with sinus rhythm (SR) in 370 patients, $\mathrm{AF}$ (as the leading rhythm) in 150 patients, paced rhythm in 54 patients and "other" rhythm in 2 patients. Four hundred and two patients received beta-blockers before index hospitalization, including: carvedilol (188 patients), bisoprolol (93), metoprolol (91), sotalol (13), nebivolol (7), propranolol (5), atenolol
(3) and betaxolol (2 patients). There was no distinction between metoprolol succinate and metoprolol tartrate in the Heart Failure Pilot Survey Case Report Forms. Only 39 patients $(9.7 \%$ out of 402 patients) received target doses of beta-blockers recommended by the current guidelines (i.e. bisoprolol $10 \mathrm{mg}$ daily, carvedilol $50 \mathrm{mg}$ daily, metoprolol $200 \mathrm{mg}$ daily and nebivolol $10 \mathrm{mg}$ daily) [4].

Median NYHA class at admission was III (IQR: II-IV). Median left ventricular ejection fraction (LVEF) in the study group was 37\% (IQR: 27-49\%).

\section{Primary endpoint}

Twenty-one patients (3.5\% of the study group) died during index hospitalization. Compared to patients who survived, patients who died were older, more often had a history of stroke or transient ischemic attack (TIA). These patients were characterized by several characteristics at admission: worse clinical presentation (higher NYHA class), higher HR, lower systolic and diastolic blood pressure, lower LVEF, lower glomerular filtration rate (GFR) and lower natrium and hemoglobin concentrations, as shown in Table 1.

In univariate analyses, factors that predicted death during index hospitalization were: higher age, a history of a previous stroke or TIA, higher NYHA class at admission, higher HR at admission, lower systolic and diastolic blood pressure at admission, lower LVEF, lower GFR and lower hemoglobin and natrium concentrations at admission. A trend was observed for previous statin treatment and acute coronary syndrome as a reason for index hospitalization. Univariate analyses are shown in Table 2.

In multivariate analysis, higher $\mathrm{HR}$ at admission (OR 1.594 [per 10 bpm]; 95\% CI 1.061-2.395; $\mathrm{p}=0.0248)$ and lower natrium concentration at admission (OR 0.767 [per $1 \mathrm{mmol} / \mathrm{L}$ ]; 95\% CI $0.618-0.952 ; \mathrm{p}=0.0162$ ) were the only independent predictors of in-hospital mortality (Table 3 ). A trend was observed for lower $\operatorname{LVEF}(\mathrm{p}=0.0591)$ and lower hemoglobin concentrations $(\mathrm{p}=0.0709)$. Due to lack of complete data for some of the patients in the registry, the multivariate analysis included only those patients (425 out of 598) for whom all required parameters were available.

We also performed additional analyses, separately for 370 patients with SR and for 150 patients with $\mathrm{AF}$ at hospital admission, to evaluate the impact of resting HR at admission on in-hospital mortality in those two subgroups of patients. In univariate analyses we observed a significant association between higher HR and primary endpoint 
Table 1. Baseline characteristics of patients who survived and patients who died during hospitalization. In each bar, a total number (n) of patients for whom the given variable was available in the registry is shown. Continuous and ordinal variables are shown as a median value and interquartile range (IQR).

\begin{tabular}{|c|c|c|c|}
\hline & Alive $(n=577)$ & Dead $(n=21)$ & $\mathbf{P}$ \\
\hline \multicolumn{4}{|l|}{ Demographics } \\
\hline Age [years] & $69(58-77) ; n=577$ & $80(67-84) ; n=21$ & 0.0036 \\
\hline Male & $64.8 \%(374 / 577)$ & $57.1 \%(12 / 21)$ & 0.49 \\
\hline Body mass index $\left[\mathrm{kg} / \mathrm{m}^{2}\right]$ & $27.7(24.4-31.3), n=514$ & $26.2(24.8-31.6), n=14$ & 0.85 \\
\hline \multicolumn{4}{|l|}{ Heart failure (HF) } \\
\hline Ischemic etiology of HF & $59.8 \%(345 / 577)$ & $61.9 \%(13 / 21)$ & 1.0 \\
\hline LVEF [\%] & $37(27-50), n=510$ & $27(20-36), n=15$ & 0.0092 \\
\hline \multicolumn{4}{|l|}{ Medical history } \\
\hline Current smoking & $55.5 \%(320 / 577)$ & $57.1 \%(12 / 21)$ & 1.0 \\
\hline Coronary artery disease & $58.5 \%(337 / 576)$ & $71.4 \%(15 / 21)$ & 0.27 \\
\hline Previous stroke or TIA & $9.4 \%(54 / 575)$ & $23.8 \%(5 / 21)$ & 0.046 \\
\hline Diabetes mellitus & $35.0 \%(202 / 577)$ & $47.6 \%(10 / 21)$ & 0.25 \\
\hline Hypertension & $66.7 \%(385 / 577)$ & $76.2 \%(16 / 21)$ & 0.47 \\
\hline COPD & $12.9 \%(74 / 575)$ & $14.3 \%(3 / 21)$ & 0.74 \\
\hline Chronic renal disease & $22.4 \%(129 / 576)$ & $38.1 \%(8 / 21)$ & 0.11 \\
\hline \multicolumn{4}{|l|}{ Previous pharmacotherapy } \\
\hline Previous treatment with ACEI & $61.6 \%(333 / 541)$ & $63.2 \%(12 / 19)$ & 1.0 \\
\hline Previous treatment with ARB & $6.9 \%(37 / 539)$ & $5.3 \%(1 / 19)$ & 1.0 \\
\hline Previous treatment with ACEI or ARB & $1.5 \%(8 / 539)$ & $0.0 \%(0 / 19)$ & 1.0 \\
\hline Previous treatment with beta-blockers & $72.3 \%(391 / 541)$ & $57.9 \%(11 / 19)$ & 0.19 \\
\hline Previous treatment with aldosterone antagonists & $41.4 \%(224 / 541)$ & $42.1 \%(8 / 19)$ & 1.0 \\
\hline Previous treatment with statin & $53.0 \%(287 / 541)$ & $31.6 \%(6 / 19)$ & 0.0997 \\
\hline \multicolumn{4}{|l|}{ Index hospitalization } \\
\hline ACS as a cause of HF decompensation & $29.3 \%(169 / 576)$ & $47.6 \%(10 / 21)$ & 0.088 \\
\hline $\mathrm{HR}$ at admission [bpm] & $80(70-100), n=577$ & $100(80-130), n=21$ & 0.019 \\
\hline $\mathrm{AF}$ at admission & $34.1 \%(197 / 577)$ & $42.8 \%(9 / 21)$ & 0.48 \\
\hline SBP at admission [mm Hg] & $130(115-150), n=576$ & $110(90-130), n=21$ & 0.001 \\
\hline DBP at admission [mm Hg] & $80(70-90), n=576$ & $70(60-80), n=21$ & 0.0017 \\
\hline NYHA class at admission & III (II-IV), n = 575 & IV (IV-IV), $\mathrm{n}=21$ & $<0.0001$ \\
\hline NYHA class I & $1.4 \%(8 / 575)$ & $0.0 \%(0 / 21)$ & \\
\hline NYHA class II & $24.7 \%(142 / 575)$ & $0.0 \%(0 / 21)$ & \\
\hline NYHA class III & $49.4 \%(284 / 575)$ & $23.8 \%(5 / 21)$ & \\
\hline NYHA class IV & $24.5 \%(141 / 575)$ & $76.2 \%(16 / 21)$ & \\
\hline Hemoglobin concentration at admission [g/dL] & $13.3(12.1-14.6), n=564$ & $12.1(11.0-13.7), \mathrm{n}=21$ & 0.014 \\
\hline GFR at admission $\left[\mathrm{mL} / \mathrm{min} / 1.73 \mathrm{~m}^{2}\right]$ & $65.9(46.2-93.3), \mathrm{n}=509$ & $42.9(30.3-58.3), n=13$ & 0.0192 \\
\hline Natrium concentration at admission $[\mathrm{mmol} / \mathrm{L}]$ & $138.9(136.0-141.0), n=568$ & $135.0(132.9-138.8), n=21$ & 0.0052 \\
\hline
\end{tabular}

HF — heart failure; LVEF — left ventricular ejection fraction; TIA — transient ischemic attack; COPD — chronic obstructive pulmonary disease; ACEI - angiotensin-converting-enzyme inhibitor; ARB - angiotensin receptor blocker; ACS — acute coronary syndrome; HR - heart rate; $\mathrm{AF}$ - atrial fibrillation; SBP — systolic blood pressure; DBP — diastolic blood pressure; NYHA — New York Heart Association; GFR — glomerular filtration rate

in patients with AF (OR 1.37 [per $10 \mathrm{bpm}$ ]; 95\% CI 1.00-1.87; $\mathrm{p}=0.0495)$ and a borderline association in patients with SR (OR 1.26 [per $10 \mathrm{bpm}$; 95\% CI 0.99-1.61; $\mathrm{p}=0.058)$. However, none of the predictive factors from the univariate analyses was found to be an independent risk factor in multivariate analyses. That was most probably a result of insufficient statistical power due to a very small number of events in both subgroups (4 deaths in 132 patients with complete data available for multivariate analysis in the subgroup with $\mathrm{AF}$ and 5 deaths in 274 patients with complete data available for multivariate analysis in the subgroup with SR). 
Table 2. Univariate analyses of predictors of in-hospital mortality.

\begin{tabular}{|c|c|c|}
\hline & Odds ratio $(95 \% \mathrm{CI})$ & $\mathbf{P}$ \\
\hline \multicolumn{3}{|l|}{ Demographics } \\
\hline Age [per 10 years] & $1.79(1.16-2.75)$ & 0.008 \\
\hline Male & $0.72(0.30-1.73)$ & 0.46 \\
\hline Body mass index [per $1 \mathrm{~kg} / \mathrm{m}^{2}$ ] & $1.00(0.91-1.10)$ & 0.99 \\
\hline \multicolumn{3}{|l|}{ Heart failure (HF) } \\
\hline Ischemic etiology of HF & $1.09(0.45-2.68)$ & 0.84 \\
\hline Left ventricular ejection fraction [per $5 \%$ ] & $0.74(0.59-0.93)$ & 0.011 \\
\hline \multicolumn{3}{|l|}{ Medical history } \\
\hline Current smoking & $1.06(0.44-2.57)$ & 0.89 \\
\hline Coronary artery disease & $1.78(0.68-4.64)$ & 0.24 \\
\hline Previous stroke or TIA & $3.03(1.07-8.59)$ & 0.037 \\
\hline Diabtes mellitus & $1.70(0.71-4.1)$ & 0.24 \\
\hline Hypertension & $1.61(0.58-4.47)$ & 0.36 \\
\hline Chronic obstructive pulmonary disease & $1.133(0.33-3.94)$ & 0.84 \\
\hline Chronic renal disease & $2.12(0.86-5.23)$ & 0.102 \\
\hline \multicolumn{3}{|l|}{ Previous pharmacotherapy } \\
\hline Previous treatment with ACEI & $1.07(0.62-2.77)$ & 0.88 \\
\hline Previous treatment with ARB & $0.76(0.10-5.83)$ & 0.79 \\
\hline Previous treatment with $\mathrm{ACEI}$ or ARB & $1.0(0-999)$ & 0.99 \\
\hline Previous treatment with beta-blockers & $0.53(0.21-1.33)$ & 0.17 \\
\hline Previous treatment with aldosterone antagonists & $1.03(0.41-2.60)$ & 0.95 \\
\hline Previous treatment with statin & $0.41(0.15-1.08)$ & 0.072 \\
\hline \multicolumn{3}{|l|}{ Index hospitalization } \\
\hline ACS as a cause of HF decompensation & $2.20(0.92-5.23)$ & 0.078 \\
\hline Heart rate at admission [per $10 \mathrm{bpm}$ ] & $1.27(1.08-1.49)$ & 0.003 \\
\hline Atrial fibrillation at admission & $1.46(0.60-3.51)$ & 0.40 \\
\hline Systolic BP at admission [per 10 mm Hg] & $0.72(0.59-0.88)$ & 0.0015 \\
\hline Diastolic BP at admission [per $10 \mathrm{~mm} \mathrm{Hg}$ ] & $0.57(0.42-0.79)$ & 0.0007 \\
\hline NYHA class at admission & $7.52(2.9-19.4)$ & $<0.0001$ \\
\hline Hemoglobin concentration at admission [per $1 \mathrm{~g} / \mathrm{dL}$ ] & $0.75(0.62-0.93)$ & 0.007 \\
\hline GFR at admission [per $10 \mathrm{~mL} / \mathrm{min} / 1.73 \mathrm{~m}^{2}$ ] & $0.80(0.65-0.99)$ & 0.043 \\
\hline Natrium concentration at admission [per $1 \mathrm{mmol} / \mathrm{L}$ ] & $0.87(0.79-0.94)$ & 0.001 \\
\hline
\end{tabular}

$\mathrm{Cl}$ - confidence interval; HF — heart failure; TIA — transient ischemic attack; ACEI — angiotensin-converting-enzyme inhibitor; ARB — angiotensin receptor blocker; ACS - acute coronary syndrome; BP - blood pressure; NYHA - New York Heart Association; GFR - glomerular filtration rate

\section{Secondary endpoints}

Median duration of hospital stay was 7 (IQR: 4-11) days, and median time spent in ICCU was 1 (IQR: $0-5)$ day. Sixty-two (10.4\%) patients required inotropic support and $469(78.4 \%)$ patients received diuretic treatment. Median NYHA class at discharge was II (IQR: II-III).

In univariate analyses, higher HR at hospital admission was associated with a more frequent use of inotropic support ( $\mathrm{p}=0.0462$; OR [per $10 \mathrm{bpm}]$ 1.115; 95\% CI 1.002-1.241) and diuretics $(\mathrm{p}=0.0426$; OR [per $10 \mathrm{bpm}$ ] 1.104; 95\% CI 1.003-1.215), worse clinical status (higher NYHA class $)$ at discharge $(\mathrm{p}=0.0483 ; \mathrm{r}=0.0819)$, and longer hospital stay ( $\mathrm{p}=0.0303 ; \mathrm{r}=0.0894)$. There was no relation between HR and time in ICCU $(p=0.1644)$.

\section{Discussion}

In the Polish population of patients hospitalized for HF, RHR at admission was found to be a predictor of in-hospital mortality, independently of other markers of the severity of HF decompensation, such as blood pressure and clinical status (NYHA class) at admission. An increase in HR of $10 \mathrm{bpm}$ was followed by an almost $60 \%$ increase 
Table 3. Multivariate analysis of predictors of in-hospital mortality $(n=425)$.

\begin{tabular}{|c|c|c|}
\hline & Odds ratio $(95 \% \mathrm{Cl})$ & $\mathbf{P}$ \\
\hline Age [per 10 years] & $1.678(0.578-4.868)$ & 0.3408 \\
\hline Left ventricular ejection fraction [per 5\%] & $0.639(0.401-1.017)$ & 0.0591 \\
\hline Previous stroke or TIA & $0.975(0.061-15.677)$ & 0.9860 \\
\hline Previous treatment with statin & $0.518(0.054-4.943)$ & 0.5674 \\
\hline ACS as a cause of HF decompensation & $0.689(0.042-11.344)$ & 0.7942 \\
\hline HR at admission [per $10 \mathrm{bpm}]$. & $1.594(1.061-2.395)$ & 0.0248 \\
\hline Systolic BP at admission [per $10 \mathrm{~mm} \mathrm{Hg}$ ] & $0.534(0.196-1.453)$ & 0.2195 \\
\hline Diastolic BP at admission [per $10 \mathrm{~mm} \mathrm{Hg}$ ] & $1.997(0.555-7.183)$ & 0.2897 \\
\hline NYHA class at admission & $3.354(0.554-20.319)$ & 0.1880 \\
\hline Hemoglobin concentration at admission [per $1 \mathrm{~g} / \mathrm{dL}$ ] & $0.576(0.316-1.048)$ & 0.0709 \\
\hline GFR at admission [per $10 \mathrm{~mL} / \mathrm{min} / 1.73 \mathrm{~m}^{2}$ ] & $0.883(0.559-1.395)$ & 0.5938 \\
\hline Natrium concentration at admission [per $1 \mathrm{mmol} / \mathrm{L}$ ] & $0.767(0.618-0.952)$ & 0.0162 \\
\hline
\end{tabular}

$\mathrm{Cl}$ — confidence interval; TIA — transient ischemic attack; ACS — acute coronary syndrome; HF — heart failure; HR — heart rate; BP — blood pressure; NYHA — New York Heart Association; GFR — glomerular filtration rate

in the risk of death during hospitalization. The analysis included patients with SR, as well as patients with $\mathrm{AF}$ (as the leading rhythm) and patients with paced rhythm at hospital admission. Separate analyses of subgroups with SR and AF at hospital admission yielded equivocal results due to insufficient statistical power.

RHR at admission was also associated with worse clinical course during index hospitalization, with a more frequent need for inotropic support and diuretic treatment, worse clinical status at hospital discharge and longer hospital stay in univariate analyses. However, these associations were weak, as Spearman's rank correlation coefficient (r) for relationship of HR with NYHA class and hospital stay were below 0.1 .

Raised RHR is a known risk factor for unfavorable outcome in HF. This was most evidently demonstrated in the SHIFT trial, which randomized 6,558 patients with chronic, symptomatic $\mathrm{HF}$, stable on current medication, with LVEF of $35 \%$ or lower, SR and resting HR over $70 \mathrm{bpm}$ to ivabradine or placebo. After a median follow-up for almost 2 years, an $18 \%$ risk reduction in primary endpoint (cardiovascular death or hospital admission for worsening HF) was observed for patients allocated to ivabradine group [5]. A post-hoc analysis demonstrated that this effect was completely attributable to HR reduction on ivabradine therapy, as treatment results were neutralized after adjustment for change of HR at 28 days. In patients receiving placebo, baseline RHR over $87 \mathrm{bpm}$ was associated with more than 2 -fold higher risk for primary endpoint than baseline HR below $72 \mathrm{bpm}$
[3]. Unlike the SHIFT trial, our study included patients with decompensated $\mathrm{HF}$ rather than stable chronic HF, irrespective of LVEF, with both, SR and $\mathrm{AF}$, and focused on short-term prognosis.

A recent post-hoc analysis of another large, randomized clinical trial - Candesartan in Heart Failure: Assessment of Reduction in Mortality and Morbidity (CHARM) delivered results similar to conclusions from the SHIFT trial [6]. In a cohort of 7,599 patients with chronic, symptomatic HF, baseline HR in the highest tertile (with median HR of $85 \mathrm{bpm}$ ) was associated with a significantly higher risk of cardiovascular death and HF hospitalization after 38 months compared with the lowest HR tertile (with median HR of $60 \mathrm{bpm}$ ). The relationship between HR and outcomes was similar in patients with LVEF below and over $40 \%$. However, baseline HR had no predictive value in patients with AF [6].

A few other small, prospective, observational studies confirmed significance of RHR for prognosis in chronic HF [7, 8]. Interestingly, higher HR correlated with increased risk of arrhythmic events in patients with dilated cardiomyopathy and an implantable cardioverter-defibrillator [9].

Baseline HR at hospital admission was also found to influence outcome in patients with acute, decompensated HF. Recently, three independent risk scores assessing short-term prognosis in patients with acute HF have been developed [10-12]. All these three predictive models were derived from data from large cohorts of patients admitted for acute HF (including 7,433; 2,015 and 5,306 patients) and stratified the risk of death at 7 
days, death or HF worsening at 7 days, and death at 30 days, respectively. In all these studies, baseline HR turned out to be an independent prognostic factor and was incorporated in risk stratification models, together with other predictive factors, including age, comorbid conditions, baseline laboratory findings and other presenting clinical features, such as systolic blood pressure. However, contrary to our study, none of these three studies included LVEF in the multivariate analysis [10-12].

The association between HR and prognosis in HF might partially explain the beneficial effect of beta-blockers in HF patients. Guidelines recommend that patients with $\mathrm{HF}$ receive beta-blockers in doses used in the trials that have proven their efficacy [4]. However, a meta-analysis of 23 prospective, randomized, placebo-controlled trials with beta-blockers, including over 19,000 patients with $\mathrm{HF}$, revealed significant impact of achieved HR reduction on all-cause mortality, with no relationship between mortality and beta-blockers dosing. Every HR reduction of $5 \mathrm{bpm}$ with beta-blocker treatment was followed by an $18 \%$ reduction in the risk of death [13]. Another study, including 421 hospitalized HF patients, demonstrated that not the discharge HR itself, but the extent of HR reduction achieved during treatment with beta-blockers determines the risk of future cardiac events [14].

The second independent predictor of in-hospital mortality in our analysis was lower natrium concentrations. Hyponatremia is frequently observed in patients with severe HF. Data from registries and randomized controlled trials indicate that $12-27 \%$ of patients admitted to hospital for HF are hyponatremic [15-19]. In HF, hyponateremia is believed to result from increased concentrations of antidiuretic hormone (ADH, vasopressin), the secretion of which is stimulated by reduced systemic arterial blood pressure due to a low cardiac output, even in patients with volume overload and fluid retention. Long-term therapy with loop diuretics may aggravate hyponatremia [20].

Hyponatremia had previously been associated with unfavorable prognosis in HF. In observational studies, registries and post-hoc analyses of randomized clinical trials, it was reported to correlate with all-cause and cardiac mortality (both in-hospital and long-term) as well as with the risk of re-hospitalization for HF [12, 15-19, 21-23].

So far, it is not clear whether hyponatremia itself deteriorates clinical outcome in $\mathrm{HF}$ or whether it is merely a marker of severity of HF or other comorbid conditions [20]. Interestingly, despite a proven relationship between hyponatremia and prognosis in HF, treatment with ADH receptor antagonists, such as tolvaptan, had no impact on mortality in HF [24]. Observational studies evaluating changes in plasma natrium in patients hospitalized for HF have brought conflicting results, with some evidence that correction of hyponatremia might lead to improvement in outcome [15, 18, 25-27].

In our study, in the multivariate analysis of independent predictors of in-hospital mortality we also observed a trend for lower LVEF and lower hemoglobin concentrations at admission. Both of these variables are known prognostic factors in $\mathrm{HF}$ patients [12, 21-23, 28-30]. It seems possible that due to a relatively small number of events these factors did not reach statistical significance in our analysis. In a cohort of 48,612 patients hospitalized for $\mathrm{HF}$ and enrolled in the Organized Program to Initiate Lifesaving Treatment in Hospitalized Patients with Heart Failure (OPTIMIZE-HF) registry independent predictors of in-hospital mortality included i.a. resting HR, natrium concentrations and presence of left ventricular systolic dysfunction [21].

\section{Limitations of the study}

The limitations of our study result from the type of data we analyzed. The advantage of registries is that they include a broad, diverse, real-life spectrum of patients, rather than a narrow, carefully selected patient subgroup as in clinical trials. However, important drawbacks of registries are: their retrospective and observational character, simplifications necessary for data unification for analysis, limited number of data collected, as well as incompleteness of the data. In our study data of $425(71 \%)$ out of 598 patients were complete and available for multivariate analysis. Furthermore, some potentially important variables, such as concentrations of B-type natriuretic peptide, were not available for analysis.

\section{Conclusions}

In Polish patients hospitalized for HF, higher $\mathrm{HR}$ at hospital admission was associated with increased in-hospital mortality.

\section{Acknowledgements}

All analyses were conducted based on data from the Polish part of the Heart Failure Pilot Survey, coordinated nationwide by Professor Jarosław Drożdż. 


\section{Participating centers, investigators and data collection officers}

1. Zabrze (ul. Szpitalna): L. Poloński, M.Zembala, P. Rozentryt, J. Niedziela, J. Wacławski, M. Świetlińska

2. Wrocław: P. Ponikowski, E. Jankowska

3. Warszawa (ul. Banacha): G. Opolski, A. Kapłon-Cieślicka, M. Marchel, P. Balsam

4. Wałbrzych: R. Szełemej, T. Nowak

5. Biała: Z. Juszczyk, S. Stankala

6. Kraków (ul. Skarbowa): E. Mirek-Bryniarska, M. Zabojszcz, A. Grzegórzko

7. Zamość: A. Kleinrok, G. Prokop-Lewicka

8. Łódź (ul. Sterlinga): J. Drożdż, K. Wojtczak-Soska, A. Retwiński

9. Bydgoszcz: W. Sinkiewicz, W. Gilewski, J. Pietrzak

10. Kielce: B. Wożakowska-Kapłon, B. Sosnowska-Posiarska, R. Bartkowiak

11. Poznań: S. Grajek, E. Straburzyńska-Migaj, H. Wachowiak-Baszyńska, A. Katarzyńska-Szymańska

12. Sochaczew: E. Piasecka-Krysiak, J. Zambrzycki

13. Kraków (ul. Prądnicka): J. Nessler, K. Bury

14. Łódź (ul. Kniaziewicza): M. Broncel, A. Poliwczak

15. Zabrze (ul. M. Curie-Skłodowskiej): E. Nowalany-Kozielska, A. Rolnik, J. Jojko

16. Kalisz: J. Tarchalski, G. Borej, R. Bartliński

17. Suwałki: J. Korszun

18. Bełchatów: D. Stachurski

19. Gdańsk: A. Rynkiewicz, J. Bellwon

20. Sieradz: P. Ruszkowski, G. Bednarczyk

21. Warszawa (ul. Solec): A. Mamcarz, A. Folga, M. Wełnicki

22. Kluczbork: A. Krzemiński

23. Częstochowa: P. Kardaszewicz, J. Gabryel, M. Łazorko-Piega

24. Gorlice: P. Kukla

25. Chełmża: P. Kasztelowicz

26. Sosnowiec: J. Olender

27. Zielona Góra: B. Kudlińska

28. Gostynin-Kruk: M. Pagórek, S. Olczyk

29. Rzeszów: J. Kuźniar, T. Rzeszuto

Conflict of interest: none declared

\section{References}

1. McMurray JJ, Adamopoulos S, Anker SD et al. ESC Guidelines for the diagnosis and treatment of acute and chronic heart failure 2012: The Task Force for the Diagnosis and Treatment of Acute and Chronic Heart Failure 2012 of the European Society of Cardiology. Eur Heart J. 2012; 33: 1787-1847.
2. Maggioni AP, Dahlström U, Filippatos G et al. EURObservational Research Programme: The Heart Failure Pilot Survey (ESC-HF Pilot). Eur J Heart Fail, 2010; 12: 1076-1084.

3. Böhm M, Swedberg K, Komajda M et al. Heart rate as a risk factor in chronic heart failure (SHIFT): The association between heart rate and outcomes in a randomised placebo-controlled trial. Lancet, 2010; 376: 886-894.

4. McMurray JJ, Adamopoulos S, Anker SD et al. ESC Guidelines for the diagnosis and treatment of acute and chronic heart failure 2012: The Task Force for the Diagnosis and Treatment of Acute and Chronic Heart Failure 2012 of the European Society of Cardiology. Developed in collaboration with the Heart Failure Association (HFA) of the ESC. Eur Heart J, 2012; 33: 1787-1847.

5. Swedberg K, Komajda M, Böhm M et al. Ivabradine and outcomes in chronic heart failure (SHIFT): A randomised placebocontrolled study. Lancet, 2010; 376: 875-885.

6. Castagno D, Skali H, Takeuchi M et al. Association of heart rate and outcomes in a broad spectrum of patients with chronic heart failure: Results from the CHARM (Candesartan in Heart Failure: Assessment of Reduction in Mortality and morbidity) program. J Am Coll Cardiol, 2012; 59: 1785-1795.

7. Oh C, Chang HJ, Sung JM et al. Prognostic Estimation of Advanced Heart Failure With Low Left Ventricular Ejection Fraction and Wide QRS Interval. Korean Circ J, 2012; 42: 659-667.

8. Fujita B, Franz M, Goebel B et al. Prognostic relevance of heart rate at rest for survival and the quality of life in patients with dilated cardiomyopathy. Clin Res Cardiol, 2012; 101: 701-707.

9. Calé R, Mendes M, Brito J et al. Resting heart rate is a powerful predictor of arrhythmic events in patients with dilated cardiomyopathy and implantable cardioverter-defibrillator. Rev Port Cardiol, 2011; 30: 199-212.

10. Lee DS, Stitt A, Austin PC et al. Prediction of heart failure mortality in emergent care: A cohort study. Ann Intern Med, 2012; 156: 767-775.

11. O'Connor CM, Mentz RJ, Cotter G, et al. The PROTECT inhospital risk model: 7-day outcome in patients hospitalized with acute heart failure and renal dysfunction. Eur J Heart Fail, 2012; 14: 605-612.

12. Lassus J, Gayat E, Mueller C et al. Incremental value of biomarkers to clinical variables for mortality prediction in acutely decompensated heart failure: The Multinational Observational Cohort on Acute Heart Failure (MOCA) study. Int J Cardiol, 2013; 168: 2186-2194.

13. McAlister FA, Wiebe N, Ezekowitz JA, Leung AA, Armstrong PW. Meta-analysis: beta-blocker dose, heart rate reduction, and death in patients with heart failure. Ann Intern Med, 2009; 150: 784-794.

14. Takahama H, Yokoyama H, Kada A et al. The extent of heart rate reduction during hospitalization using beta-blockers, not the achieved heart rate itself at discharge, predicts the clinical outcome in patients with acute heart failure syndromes. J Cardiol, 2013; 61: 58-64.

15. Gheorghiade M, Rossi JS, Cotts W et al. Characterization and prognostic value of persistent hyponatremia in patients with severe heart failure in the ESCAPE Trial. Arch Intern Med, 2007; 167: 1998-2005.

16. Sato N, Gheorghiade M, Kajimoto K et al. Hyponatremia and inhospital mortality in patients admitted for heart failure (from the ATTEND registry). Am J Cardiol, 2013; 111: 1019-1025.

17. Gheorghiade M, Abraham WT, Albert NM et al. Relationship between admission serum sodium concentration and clinical out- 
comes in patients hospitalized for heart failure: An analysis from the OPTIMIZE-HF registry. Eur Heart J, 2007; 28: 980-988.

18. Klein L, O'Connor CM, Leimberger JD et al. Lower serum sodium is associated with increased short-term mortality in hospitalized patients with worsening heart failure: Results from the Outcomes of a Prospective Trial of Intravenous Milrinone for Exacerbations of Chronic Heart Failure (OPTIME-CHF) study. Circulation, 2005; 111: 2454-2460.

19. Balling L, Schou M, Videbæk L et al. Prevalence and prognostic significance of hyponatraemia in outpatients with chronic heart failure. Eur J Heart Fail, 2011; 13: 968-973.

20. Goldsmith SR. Hyponatremia and outcomes in patients with heart failure. Heart, 2012; 98: 1761-1762.

21. Abraham WT, Fonarow GC, Albert NM et al. Predictors of in-hospital mortality in patients hospitalized for heart failure: Insights from the Organized Program to Initiate Lifesaving Treatment in Hospitalized Patients with Heart Failure (OPTIMIZE-HF). J Am Coll Cardiol, 2008; 52: 347-356.

22. O'Connor CM, Abraham WT, Albert NM et al. Predictors of mortality after discharge in patients hospitalized with heart failure: an analysis from the Organized Program to Initiate Lifesaving Treatment in Hospitalized Patients with Heart Failure (OPTIMIZE-HF). Am Heart J, 2008; 156: 662-673.

23. Parissis JT, Ikonomidis I, Rafouli-Stergiou P et al. Clinical characteristics and predictors of in-hospital mortality in acute heart failure with preserved left ventricular ejection fraction. Am J Cardiol, 2011; 107: 79-84.
24. Konstam MA, Gheorghiade M, Burnett JC Jr et al. Effects of oral tolvaptan in patients hospitalized for worsening heart failure: the EVEREST Outcome Trial. JAMA, 2007; 297: 1319-1331.

25. Lee SE, Choi DJ, Yoon $\mathrm{CH}$ et al. Improvement of hyponatraemia during hospitalisation for acute heart failure is not associated with improvement of prognosis: an analysis from the Korean Heart Failure (KorHF) registry. Heart, 2012; 98: 1798-1804.

26. Madan VD, Novak E, Rich MW. Impact of change in serum sodium concentration on mortality in patients hospitalized with heart failure and hyponatremia. Circ Heart Fail, 2011; 4: 637-643.

27. Rossi J, Bayram M, Udelson JE et al. Improvement in hyponatremia during hospitalization for worsening heart failure is associated with improved outcomes: insights from the Acute and Chronic Therapeutic Impact of a Vasopressin Antagonist in Chronic Heart Failure (ACTIV in CHF) trial. Acute Card Care, 2007; 9: 82-86.

28. Lu KJ, Kearney LG, Hare DL et al. Cardiorenal anemia syndrome as a prognosticator for death in heart failure. Am J Cardiol, 2013; 111: $1187-1191$.

29. von Haehling S, van Veldhuisen DJ, Roughton M et al. Anaemia among patients with heart failure and preserved or reduced ejection fraction: results from the SENIORS study. Eur J Heart Fail, 2011; 13: 656-663.

30. Stewart T, Freeman J, Stewart J, Sullivan A, Ward C, Tofler GH. Anaemia in heart failure: a prospective evaluation of clinical outcome in a community population. Heart Lung Circ, 2010; 19: 730-735. 